\title{
O PRONAF E A INSERÇÃO TÉCNICO-PRODUTIVA NAS UNIDADES FAMILIARES DE SERGIPE
}

\section{THE PRONAF AND THE TECHNICAL-PRODUCTIVE INSERTION IN FAMILY OF SERGIPE UNITS}

\section{EL PRONAF Y LA INSERCIÓN TÉCNICO-PRODUCTIVA EN LAS UNIDADES FAMILIARES DE SERGIPE}

\author{
Diana Mendonça de Carvalho ${ }^{1}$ \\ https://orcid.org/0000-0001-5934-8165 \\ José Eloízio da Costa ${ }^{2}$ \\ https://orcid.org/0000-0002-3777-5403
}

Submissão: 26/11/2019 / Aceito: 09/08/2020.

\section{Resumo}

O Programa Nacional de Fortalecimento da Agricultura Familiar (Pronaf) é uma ação governamental com 24 anos de existência. Está presente em praticamente todos os municípios brasileiros e se firma entre os pequenos agricultores como auxiliar no combate à pobreza rural. A partir disso, o trabalho objetiva analisar a evolução e as mudanças socioespaciais promovidas pelo Pronaf em Sergipe, em termos de inserção técnico-produtiva. A pesquisa tem caráter analítico-empírico, com base quanti e qualitativa, utilizando dados colhidos das bases do Banco Central (2005-2012) e do Instituto Brasileiro de Geografia e Estatística (IBGE), além da validação perceptiva de 76 beneficiários, quanto à importância do Programa e das instituições parceiras na sua efetivação. Conclui-se que, após o acesso ao Pronaf, houve ampliação no número de agricultores que passaram a receber assistência técnica e extensão rural, aumento na aquisição e utilização de equipamentos técnicosmecânicos, além do uso de insumos químicos modernos. A utilização desses condicionantes, principalmente após o acesso ao Pronaf, demonstra que o Programa tem sido uma experiência benéfica na promoção de mudanças socioespaciais no rural, alavancando e diversificando a produção das unidades familiares, de modo a integrá-las às demandas de mercado.

Palavras-chave: Pronaf. Agricultura Familiar. Produção. Renda.

\begin{abstract}
The National Program for Strengthening Family Agriculture (Pronaf) is a government action with 24 years of existence. It is present in practically all Brazilian municipalities and is established among small farmers as an aid in combating rural poverty. From this, the work aims to analyze the evolution and socio-spatial changes promoted by Pronaf in Sergipe, in terms of technical-productive insertion. The research has an analytical-empirical character, with quantitative and qualitative basis, using data collected from the databases of the Central
\end{abstract}

1Doutora em Geografia Agrária (UFS). dianamendoncadecarvalho@gmail.com 2Doutor em Geografia Agrária (UNESP-Rio Claro/SP). Professor Titular do Departamento e do Programa de Pós-Graduação em Geografia da Universidade Federal de Sergipe. eloizio.npgeo@ gmail.com 
Bank (2005-2012) and the Brazilian Institute of Geography and Statistics (IBGE), in addition to the perceptual validation of 76 beneficiaries, regarding the importance Program and partner institutions in its implementation. It is concluded that, after accessing Pronaf, there was an increase in the number of farmers who started to receive technical assistance and rural extension, an increase in the acquisition and use of technical-mechanical equipment, in addition to the use of modern chemical inputs. The use of these conditions, especially after accessing Pronaf, demonstrates that the Program has been a beneficial experience in promoting socio-spatial changes in rural areas, leveraging and diversifying the production of family units, in order to integrate them with market demands.

Keywords: Pronaf. Family Agriculture. Production. Income.

\section{Resumen}

El Programa Nacional para Fortalecer la Agricultura Familiar (Pronaf) es una acción gubernamental con 24 años de existencia. Está presente en prácticamente todos los municipios brasileños y se establece entre los pequeños agricultores como una ayuda para combatir la pobreza rural. A partir de esto, el trabajo tiene como objetivo analizar la evolución y los cambios socioespaciales promovidos por Pronaf en Sergipe, en términos de inserción técnico-productiva. La investigación tiene un carácter analítico-empírico, con bases cuantitativas y cualitativas, utilizando los datos recopilados de las bases de datos del Banco Central (2005-2012) y el Instituto Brasileño de Geografía y Estadística (IBGE), además de la validación perceptiva de 76 beneficiarios, con respecto a la importancia Programa e instituciones asociadas en su implementación. Se concluye que, después de acceder a Pronaf, hubo un aumento en el número de agricultores que comenzaron a recibir asistencia técnica y extensión rural, un aumento en la adquisición y uso de equipos técnico-mecánicos, además del uso de insumos químicos modernos. El uso de estas condiciones, especialmente después de acceder a Pronaf, demuestra que el Programa ha sido una experiencia beneficiosa en la promoción de cambios socio-espaciales en las zonas rurales, aprovechando y diversificando la producción de unidades familiares, para integrarlas con las demandas del mercado.

Palabras chave: Pronaf. Agricultura familiar. Producción. Ingresos

\section{INTRODUÇÃO}

O Programa Nacional de Fortalecimento da Agricultura Familiar (Pronaf) é uma ação governamental com 24 anos sendo, por isso, considerada uma política pública sedimentada e fluida, que condiciona melhorias socioespaciais no rural brasileiro. Esse programa está presente em praticamente todos os municípios brasileiros e se firma entre os pequenos agricultores como auxiliar no combate à pobreza rural.

O Pronaf nasceu com o intuito de promover o desenvolvimento de atividades e serviços agropecuários e não agropecuários em estabelecimentos rurais de agricultores familiares, a partir da concessão de financiamentos, por meio de crédito e/ou microcrédito, tornando-se uma experiência benéfica na promoção de mudanças sociais no espaço rural nacional. Esse crédito difere do crédito tradicional pelo principal público alvo, haja vista, ser 
direcionado a agricultores familiares que estão abaixo da linha de pobreza e que nunca tiveram acesso ao crédito tradicional, como o Pronaf B. Mas o programa também envolve outras modalidades de beneficiários, a partir do Pronaf Custeio e Investimento, além de linhas especiais, voltados a agricultores com maior potencialidade produtiva (MCR, 2012/2013). Essa categoria de crédito é afixada segundo produção, geração de renda e montante liberado.

Além disso, o Programa nasceu na década de 1990, por pressões de pequenos agricultores do sul e sudeste do país, que demandava uma política específica de crédito, e por influência de agências multilaterais, como a Organização das Nações Unidas para Agricultura e Alimentação (FAO) e o Banco Mundial, que motivaram a definição do Agricultor familiar como uma categoria nova no Brasil. Além disso, tivemos a contribuição em nível nacional do Instituto Nacional de Colonização e Reforma Agrária (INCRA), que referendava as demandas de muitos desses pequenos agricultores.

Ademais, o Programa tem sido aperfeiçoado, visando atender ao maior número possível de agricultores familiares em todos os municípios e regiões do País. Tal apoio se impõe também como alicerce ao desenvolvimento do campo de forma sustentável, coligado ao financiamento de projetos individuais ou coletivos, que gerem renda e bem-estar social aos agricultores familiares e aos assentados de projetos de reforma agrária. Mesmo não sendo muito discorrido entre os teóricos a relação entre Pronaf e qualidade de vida, no sentido de melhorias do bem-estar social, Carneiro e Palm (2016), a partir de outras análises, evidenciam que o Programa se faz importante no fortalecimento das economias locais e na afirmação da categoria Agricultor Familiar.

Diante do exposto, o campo da geografia agrária ganha referência na análise das mudanças que as políticas públicas condicionam no espaço geográfico. Este espaço enquanto produto da ação humana, se conecta à questão do desenvolvimento e à lógica da "justiça distributiva". No espaço rural, o desenvolvimento é vislumbrado na melhoria da qualidade de vida dos agricultores, a partir da valorização e da ampliação de suas potencialidades produtivas e geradoras de renda, autonomia e integração aos mercados, numa relação de complementariedade que se estabelece entre o rural e o urbano. Tais aspectos confluem para a afirmação dos agricultores familiares como promotores de desenvolvimento, pelo seu caráter empreendedor e potencializador das economias locais. 
Nesse contexto, o artigo objetiva analisar a evolução e as mudanças socioespaciais promovidas pelo Pronaf em Sergipe, em termos de inserção técnico-produtiva. Primeiro, através de dados colhidos da base do Banco Central (2005-2012), a partir dos quais validase a significação distributiva de contratos e montantes pelo espaço rural. Por conseguinte, avalia-se com o uso de dados do Instituto Brasileiro de Geografia e Estatística (IBGE), como tais mudanças têm se processado no espaço rural sergipano. Considerou-se, também, a percepção de 76 beneficiários quanto à importância do Programa e das instituições parceiras na sua efetivação, para a promoção de melhorias de sua realidade. Registre-se que o território analisado é constituído por $77,3 \%$ de unidades familiares de produção (90.330 estabelecimentos familiares de um total de 100.606 estabelecimentos agropecuários - IBGE, 2009), consequência do forte processo de minifundização das unidades produtivas, sobretudo no Agreste; e, posteriormente, pela subdivisão das propriedades entre membros da família, mediante herança (DINIZ, 1991).

A estrutura do trabalho está subdividida nos seguintes itens principais: Pronaf: definição, características e repercussão do financiamento da agricultura familiar brasileira; Distribuição espacial do Pronaf em Sergipe; e, Relação Pronaf e melhorias técnicoprodutivas em Sergipe; além da introdução e considerações finais.

\section{PRONAF: DEFINIÇÃO, CARACTERÍSTICAS E REPERCUSSÃO DO FINANCIAMENTO DA AGRICULTURA FAMILIAR BRASILEIRA}

O Pronaf foi criado em 1996, através da Resolução no 2.191 do Banco Central do Brasil, e regulamentado pelo Decreto Presidencial No 1.946, de 28/06/1996. Desde sua origem, o Programa nasce voltado a construção de um novo paradigma de política de desenvolvimento rural específico para o Brasil, no sentido de atender a um segmento da agricultura brasileira que é gestado pela família, em termos de capacidade técnica e de inserção nos mercados agropecuários, visando quebrar vícios do passado, como a marginalização social (CARNEIRO, 1997). Sendo assim, o Pronaf representava “[...] $a$ legitimação pelo Estado, de uma nova categoria social - os agricultores familiares - que até então era praticamente marginalizada em termos de acesso aos benefícios da política agrícola [...]" (MATTEI, 2005, p.12). 
O contexto de concepção do Programa remete às reflexões de Douglas North (2005 e 2007), no que se refere à consideração do período histórico de redemocratização do Brasil, com a implementação de mudanças institucionais integradas às demandas sociais, haja vista a Constituição de 1988 ser considerada cidadã e voltada aos interesses dos brasileiros. Nesse percurso, para a consolidação do Programa, alguns fatores foram determinantes ao longo da década de 1990, entre eles:

a) $\mathrm{O}$ movimento sindical dos trabalhadores rurais vinculado à Confederação Nacional dos Trabalhadores da Agricultura (CONTAG) e ao Departamento Nacional de Trabalhadores Rurais da Central Única dos Trabalhadores (DNTR/CUT), que reivindicavam a "reconversão e reestruturação produtiva dos agricultores familiares" (MATTEI, 2005, p. 12). Estas reinvindicações tiveram foco no Seminário realizado em Chapecó (1993) e depois nas Jornadas Nacionais de Luta - Grito da Terra Brasil (1995);

b) A criação do Programa de Valorização da Pequena Produção Rural (PROVAP), em 1994, durante o Governo de Itamar Franco, que operava com recursos do Banco Nacional de Desenvolvimento Econômico e Social (BNDES).

Ressalte-se que a reformulação da concepção e da abrangência do Provap, durante o Governo de Fernando Henrique Cardoso (1995), deu origem ao Pronaf. Na segunda gestão de FHC (1999- 2002), o Pronaf passou por uma série de mudanças institucionais que lhe deram centralidade e importância social, mantidas até hoje, com pequenas modificações, conforme delimita Zaar (2001, p. 10):

En primer lugar, dejó de pertenecer al Ministerio de Agricultura, al que estaba vinculado a la Secretaría de Desarrollo Rural (SDR), y se incorporó al Ministerio de Desarrollo Agrario (MDA). En segundo lugar, en esta nueva forma de organización, el sector de la agricultura familiar ganó importancia, con la creación de la Secretaría de la Agricultura Familiar (SAF).

Aquino e Schneider (2015) também asseveram essas mudanças institucionais, demarcando não só o marco histórico do Governo FHC, mas também estendendo às gestões de Lula e Dilma Rousseff (2003-2014), quanto à heterogeneidade da agricultura familiar e a consequente adequação do programa em termos de estrutura normativa, com fins de lhe garantir capilaridade nacional. Tal fato se impõe quando os autores informam que incialmente o desenho normativo era limitado “[...] unicamente às atividades agropecuárias, 
[passando] a prever um leque bastante diversificado de linhas de ação além do custeio e do investimento tradicionais" (AQUINO; SCHNEIDER, 2015, p. 58).

Nesse contexto, o Pronaf passou a ser um instrumento de política do Ministério do Desenvolvimento Agrário (MDA), cuja Secretaria de Agricultura Familiar (SAF) é a gestora $^{3}$. Deste modo, o Estado aparece como entidade adequada na fomentação de instituições, que constituirão arranjos institucionais mais eficientes no sentido de transformar o espaço rural brasileiro. No caso do Pronaf, os entes institucionais são demarcados nos agentes financeiros oficiais, que atuam na efetivação e na liberação dos contratos, assim como, nos organismos mediadores que liberam a documentação, a exemplo da Declaração de Aptidão, para reconhecimento do agricultor familiar como apto a ser beneficiado.

Operacionalmente, o Pronaf foi iniciado com quatro linhas de atuação:

- Financiamento da Produção (Custeio e Investimento), que auxilia as atividades produtivas em quase todo o País, segundo quatro categorias de beneficiários, à saber: Grupo A, B, C e D. Essas categorias têm base na resolução 2.629 de 10 de agosto de 1999, referenciam o nível de renda bruta anual familiar e integram as normas gerais do Manual de Crédito Rural (MCR);

- Financiamento de Infraestrutura e Serviços Municipais ${ }^{4}$;

- Capacitação e Profissionalização dos Agricultores Familiares e Técnicos;

- Financiamento da Pesquisa e Extensão Rural, como forma de transferir tecnologias para os agricultores familiares.

Dentre essas linhas de atuação, a primeira detém a maior importância e foco para o entendimento da relação entre financiamento e agricultura familiar, demonstrando que essa categoria não é homogênea em sua totalidade, apesar de se definir em características comuns. Por isso, para melhor operacionalização, a cada ano safra, foram sendo criadas diferentes linhas de crédito e adotadas novas categorias de beneficiários, as quais permitem, por via de regras, serem

\footnotetext{
${ }^{3}$ O Ministério do Desenvolvimento Agrário foi extinto em maio de 2016, quando da criação da Secretaria Especial de Agricultura Familiar e do Desenvolvimento Agrário (SEAD), ligado à Casa Civil da Presidência da República. No atual Governo (2019-2022), a SEAD foi incorporada ao Ministério da Agricultura, Pecuária e Abastecimento (MAPA) (TOLEDO, 2019).

4 Mediante a definição do Programa Nacional de Desenvolvimento Rural Sustentável (PRONAT) implementado em 2003, a linha de financiamento Infraestrutura e Serviços do PRONAF, em execução entre 1996 e 2002, foi integrada ao PRONAT e passou a ser conhecida como "Ações de Projetos de Infraestrutura e Serviços" (PROINF) (SILVA, 2018).
} 
[...] mais adequadas à realidade de cada segmento social, sendo que os encargos financeiros e os rebates visavam auxiliar mais aquelas parcelas de agricultores com menores faixas de renda e em maiores dificuldades produtivas. (MATTEI, 2014, p.59)

O financiamento de crédito para custeio da agricultura nacional, no momento de sua institucionalização, tinha por objetivo a manutenção das safras anuais, sem intervenção sobre problemas estruturais do sistema de produção dos agricultores familiares. Após 1997, essa política foi aperfeiçoada, passando a operar por modalidade. Em 1999, as taxas de juros foram reduzidas de 7,25\% para 5,75\% ao ano, o que possibilitou ampliação do número de agricultores familiares beneficiados. A partir de 2010, essas taxas diminuíram para $2 \%$ ao ano, dando maior estímulo à agricultura familiar (Plano Safra, 2010).

Para ter acesso ao Pronaf, segundo o Manual do Crédito Rural (2012), os agricultores familiares devem possuir, pelo menos, $50 \%$ de sua renda originária da atividade agropecuária; ser dono de estabelecimentos de até quatro módulos fiscais de prática agrícola e até seis módulos, de prática de atividades pecuárias; trabalhar a terra na condição de proprietário, meeiro, parceiro ou arrendatário; utilizar mão-de-obra exclusivamente familiar, podendo manter até dois empregados permanentes; residir no imóvel ou em aglomerado rural ou urbano próximo; possuir Declaração de Aptidão; e tenham obtido renda bruta familiar nos últimos doze meses que antecederam a solicitação da DAP, de até cento e sessenta mil reais ${ }^{5}$, incluída a renda proveniente de atividades desenvolvidas no estabelecimento e fora dele, por qualquer componente familiar (no caso do PRONAF B, renda de até 10 mil reais; e o Pronaf A e A/C não requeria garantia, haja vista ser público de reforma agrária) (BACEN, 2012).

Em todo caso, o Pronaf representou um alicerce de integração dos pequenos agricultores às relações de mercado, pois tem apoiado um segmento da agricultura que ficou sempre à margem das políticas públicas nacionais. Grisa e Schneider (2015) destacam que o surgimento do Programa representou o reconhecimento e a legitimação da agricultura familiar por parte do Estado (Lei no 11.326, de 24 de julho de 2006), assim como, "a inserção da agricultura familiar na agenda política nacional [...] com quase um século de atraso em relação à experiência dos países desenvolvidos que, desde o início do século XX, optaram

5 Em 2018, o Manual do Crédito Rural determinou a renda bruta familiar anual em até $\mathrm{R} \$ 415.000,00$ (quatrocentos e quinze mil reais), considerando as receitas recebidas provenientes de atividades desenvolvidas ou não no estabelecimento (MCR 651, 2018). 
pelo incentivo ao modelo familiar de produção agrícola" (AQUINO; SCHNEIDER, 2015, p. $57)$.

Além disso, o Programa originalmente buscou propiciar o aumento da produção agrícola, das ocupações produtivas, da renda e da qualidade de vida dos agricultores familiares a partir de cinco objetivos específicos: 1 - ajustar as políticas públicas de acordo com a realidade dos agricultores familiares; 2 - viabilizar infraestrutura para a melhoria do desempenho produtivo das unidades familiares; 3 - elevar o nível de profissionalização dos pequenos agricultores, dando-lhes acesso aos novos padrões de tecnologia e gestão social; 4 - estimular o acesso desses agricultores aos novos mercados de insumos e produtos; e 5 fortalecer os serviços de apoio ao desenvolvimento dessa agricultura (Manual Operacional do Pronaf, 1996, p. 08).

O progresso do Pronaf, enquanto política pública, passou a repercutir na vida financeira das famílias beneficiadas com o crédito, rompendo com vínculos de subordinação clientelistas, em que muitos pequenos agricultores, sem condições de comprar insumos e equipamentos, submetiam-se a agiotas e comerciantes das cidades interioranas, obrigandose a pagar elevadas taxas de juros. Além disso, favoreceu ampliações de ganhos macroeconômica em muitos municípios, consagrando-se como importante veículo de transferência de renda para as famílias e para os municípios pobres do Brasil, em função do estímulo à ampliação da capacidade produtiva dos agricultores beneficiados e a circulação de renda em escala local (GUANZIROLI, 2007; AQUINO; SCHNEIDER, 2015).

As evidências de ampliação da capacidade produtiva dos agricultores familiares foram atestadas pelas análises dos dados referentes ao período de 2005-2012 (BCB, 20052012). Os resultados mostram que houve crescimento importante na produção das atividades financiadas nesse período, destacando-se o trigo (398,28\%), a criação de animais $(264,58 \%)$, a soja $(177 \%)$, o café $(160 \%)$ e outras lavouras $(102,11 \%)$. Os números comprovam a existência de especialização produtiva do agricultor familiar beneficiado com o Pronaf, que corresponde às demandas não só do mercado interno, mas também às demandas da agroindústria e do próprio agronegócio. Mas, apesar do caráter produtivista definidos nesses percentuais, não se pode deixar de demarcar que há, ainda, a preocupação com a produção de subsistência, mantendo-se, em menor proporção, culturas alimentares, como o milho $(45,80 \%)$ e o arroz $(25,73 \%)$, e, mesmo em queda percentual frente aos produtos financiados, 
a manutenção produtiva da batata $(-1,5 \%)$, da mandioca $(-23,28 \%)$ e do feijão $(-26,48 \%)$ (CARVALHO, 2016).

O Pronaf tem condicionado, também, a diminuição de desigualdades de gênero no meio rural brasileiro, com ganhos em educação, aquisição de bens duráveis e condições sanitárias tanto para homens quanto para mulheres (HEREDIA; CINTRÃO, 2006). Em vista disso, o Programa se tornou um instrumento capaz de suprir algumas das principais necessidades do agricultor familiar, ao mesmo tempo que tornou possíveis mudanças espaciais, no sentido de área e de produção, da inserção desse agricultor em cadeias produtivas com fluxos comerciais e de promoção de desenvolvimento local, a partir da liberação e da circulação de montantes de recursos do Pronaf em municípios pobres, principalmente.

\section{DISTRIBUIÇÃO ESPACIAL DO PRONAF EM SERGIPE}

O Pronaf é um importante instrumento de fortalecimento da agricultura familiar sergipana, haja vista disponibilizar recursos para produção e investimentos agropecuários. Dados do Banco Central do Brasil (BCB/DIORF/DEROP/DIORE, 2005 a 2012), mostram haver dois períodos fragmentados de contratação e três para disponibilização de recursos, entre 2005 e 2012. Nesse cenário, a análise desconsidera as mudanças normativas ocorridas no Programa de 1996 a 2004, face à observação da maior expansão dos recursos, com a afirmação de regras para a concessão de crédito no Brasil, distribuindo as famílias dos agricultores beneficiários em quatro grupos distintos: Grupo A, B, C e D. Essas letras seriam institucionalmente substituida no ano de 2008, através da Resolução n ${ }^{\circ} 3.559$, de 23 de março de 2008, do Conselho Monetário Nacional, que disponibilizou distintas faixas de valores de financiamento (custeio e investimento) com diferentes taxas de juros.

Conforme os dados do BCB, o maior volume de contratos realizados em Sergipe ocorreu em 2006. Nesse ano foram efetivados aproximadamente 96 mil contratos, com a disponibilização de quase 100 milhões de reais para a agropecuária sergipana, tendo os contratos de investimento e de custeio seguido a mesma perspectiva. Esse fato é explicado 
pela mudança de metodologias contratuais, tal qual a efetivação do Agroamigo ${ }^{6}$, assim como pela facilitação de acesso a novas modalidades do Programa. Todavia, esses resultados não foram constantes durante todo o período analisado. A partir de 2007, houve redução no número de contratos, mantendo-se quase constante até 2012 (Gráfico 1).

Gráfico 01- Sergipe: Tipos de contratos do Pronaf (2005-2012)

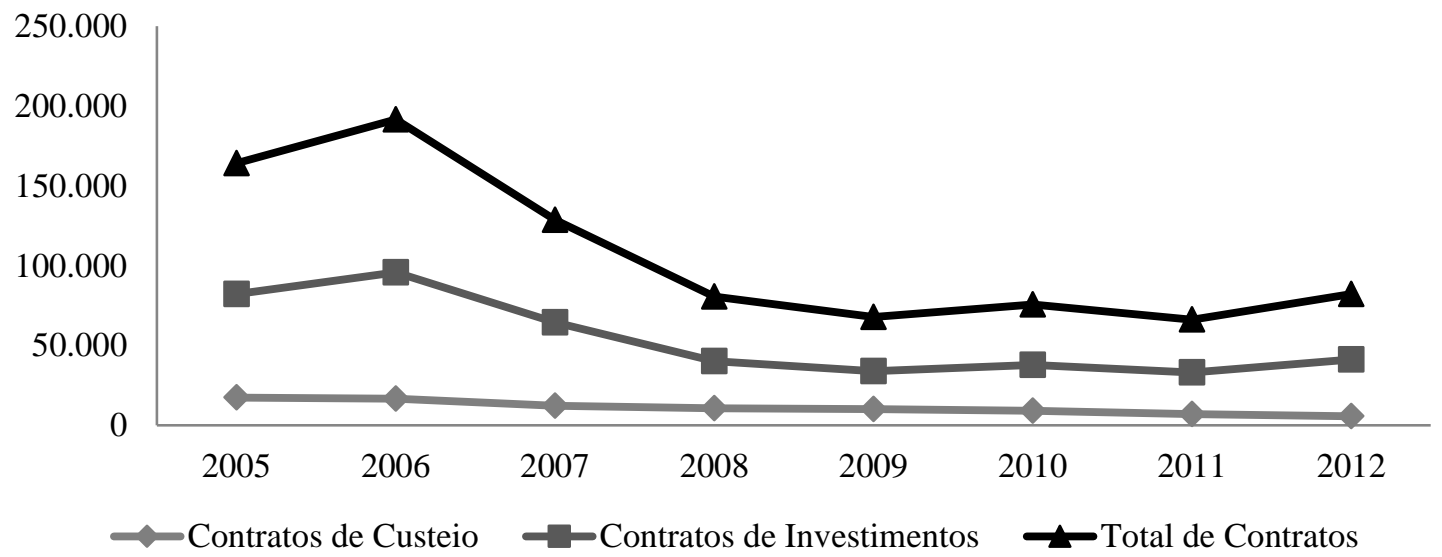

Fonte: BCB/DIORF/DEROP/DIORE, 2005-2012.

Tanto no total quanto em relação a custeio e investimento, dimensionam-se duas fases em relação ao montante de contratos: pós 2005, iniciada ainda nesse ano e permanecendo até 2006 (quando a variação de crescimento de contratos do Pronaf foi de aproximadamente 16\%); 2008 a 2012, período em que os contratos se mantiveram sem grande variação, mas com um pequeno crescimento percentual de $2,12 \%$. Entre uma fase e outra, verificou-se, no ano de 2007, uma queda de cerca de $32,8 \%$, em relação ao ano anterior. Essa variação justifica-se: 1)na falta de entendimento e de conhecimento dos novos gestores e beneficiários quanto às novas propostas implantadas pelo Governo Federal. Além disso, quando se passa a ter um entendimento da gestão e das mudanças, percebe-se a manutenção do número de contratos, de modo geral, e, também, em relação a custeio e investimentos. 2) na crise global, entre 2008-2009, que também pode ter condicionado a queda na liberação de recursos, haja vista a redução no volume de créditos disponíveis (MATTEI, 2014).

\footnotetext{
${ }^{6}$ O Agroamigo é uma das mudanças operacionalizadas ao Pronaf, a partir de 2005, com a introdução de uma metodologia inovadora processada pelo Banco do Nordeste. Essa metodologia abrangeu o Pronaf B até o ano de 2011, sendo posteriormente agregados aos outros grupos de Pronaf, à exceção dos grupos A e AC (BNB, 2020).
} 
Nesse tocante, observa-se que, de 2005 a 2012, houve decréscimo contratual em 49,86\%, mesmo com a efetivação de 428.603 contratos (soma conjunta de todos os anos), dos quais $79,25 \%$ foram demandados para investimentos, sobretudo, na edificação de infraestruturas agropecuárias; e 20,75\% para custeio, fundamentado na aquisição de insumos agrícolas e pecuários.

Os aspectos demarcados para os contratos são visíveis, também, no montante liberado. Todavia, o montante apresenta, pós 2005, um período de crescimento que vai até 2006, depois um período sem grande variação, de 2007 a 2009, e, por fim, novo impulso é observado entre 2010 e 2012 (Gráfico 2). Em relação aos montantes de recursos para custeio e investimento, a variação ocorreu nos mesmos intervalos de tempo observados nos contratos. Nesse sentido, de 2005 a 2012, foram disponibilizados cerca de R 690 milhões de reais, dos quais $61,85 \%$ direcionados a investimento e $38,15 \%$ a custeio.

Gráfico 2- Sergipe: Valor dos Contratos do Pronaf (2005-2012).

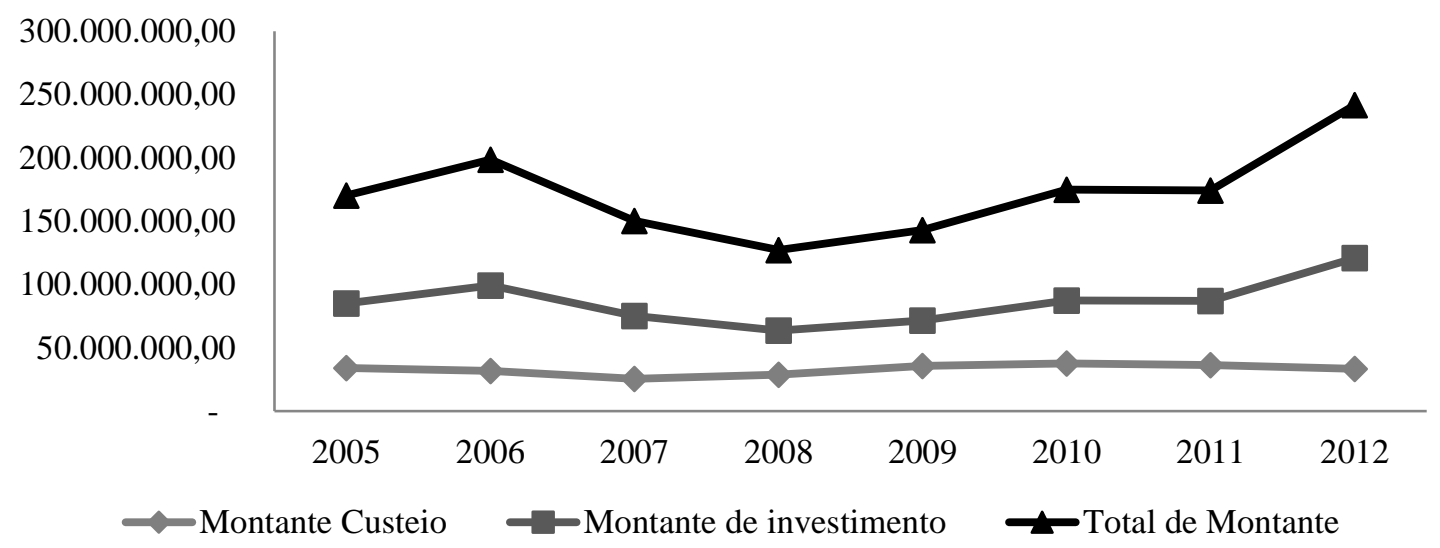

Fonte: BCB/DIORF/DEROP/DIORE, 2005-2012.

No primeiro período, o aumento de recursos justifica-se pelas mudanças realizadas pelo Governo Federal para gestão do Pronaf ainda em 2003-2004. Tais mudanças se fizeram sentir na simplificação do acesso ao crédito, na diversificação de linhas e numa nova política de assistência técnica e extensão rural aos agricultores das regiões mais pobres, com menor infraestrutura e acesso a serviços, os quais puderam, assim, aumentar a sua participação no programa (MATTEI, 2005). 
O segundo, denota o período de reconhecimento, a gestão e o funcionamento das novas metodologias, tendo variado negativamente o montante em 4,7\%. Em 2007, a Secretaria de Agricultura Familiar (SAF), por meio da Portaria ${ }^{\circ}$ 105, de 23 de novembro de 2007, considerando as atribuições do Manual do Crédito Rural (MCR), estabeleceu um controle maior sobre a operacionalização do Pronaf, no Grupo B.

O controle na liberação de recursos definido nesse período contribuiu para o decréscimo no montante liberado (MATTEI, 2014). Contudo, no último intervalo (2010 a 2012), houve um salto quantitativo em termo de montante liberado de $38,2 \%$, elucidado na simplificação e agregação de novas linhas de crédito. Nesse último ano, aliaram-se ao funcionamento do Pronaf, o Programa Garantia Safra, haja vista a grave crise sofrida no Nordeste, com a seca que acometera 102.523 pessoas em Sergipe, das quais os mais atingidos foram produtores rurais $(\mathrm{R} 7,2014)$.

Destarte, as mudanças operacionalizadas no Pronaf, desde sua criação, representam a busca por incluir segmentos de agricultores bastante heterogêneos, sobretudo no Nordeste, e também, corresponder as demandas desses atores por uma modalidade de crédito (SCHNEIDER; CAZELLA; MATTEI, 2004). Sendo assim, desde a safra 2006/2007, o Pronaf tem aumentado sucessivamente o volume de recursos destinados à agricultura familiar. Nesse tocante, enquanto os números de contratos decresceram em cerca de $50 \%$, o montante disponibilizado a beneficiários cresceu aproximadamente $42 \%$, considerando os números totais de 2005 a 2012, aspecto explicado pela disponibilização de valores atualizados, pela inclusão de novos contratos e pela renovação de outros já existentes. Em outras palavras, a adimplência dos agricultores lhes permite renovar contratos e se incluir em outra modalidade do Programa.

A evolução de contratos e de montantes liberados também foram observados por município, de 2005 a 2007. Nessa evolução demarcaram-se municípios com número de contratos superiores a 3.000. É o caso de Porto da Folha e Lagarto, que não sofreram variação nos três anos (Figura 01). Mas, Itabaianinha, Monte Alegre, Poço Redondo, Riachão do Dantas e Tobias Barreto também apresentaram saldos contratuais acima de 3.000 operações em pelo menos dois desses três anos. Porém, todo esse processo representa a incorporação de novas técnicas agrícolas produtivas, à exemplo de incrementos químicos e uso do trator 
no arar e plantar a terra, conforme vem ocorrendo também no centro-sul do Estado, com a ampliação da cultura do milho.

Considerando-se o período entre 2009 e 2011, o avanço em termos contratuais se mostra diminuto nos municípios sergipanos, em nenhum deles superior a 2.500 operações. Tal fato é explicado pela diversidade de oportunidades que o Governo Federal tem proposto aos pronafianos. Esses podem acessar outros programas, a exemplo do Programa de Aquisição de Alimentos (PAA) ou do Programa Nacional de Alimentação Escolar (PNAE), além de poderem cultivar itens necessários ao autoconsumo, sem desconsiderar a questão de taxas de juros para todas as modalidades do Pronaf. Em relação ao ano de 2011, os números podem ser justificados pelos dados de inadimplência nas várias modalidades do Pronaf, em virtude da efetividade normativa da Resolução No 4.028, de 18/11/2011, que regulamenta a composição de dívidas de crédito rural referentes a operações do mesmo tomador de crédito, a composição de dívidas por instituição financeira de crédito rural e a renegociação de dívidas. 
Figura 01- Sergipe: Evolução dos contratos do PRONAF efetivados (2005-2012) ${ }^{7}$

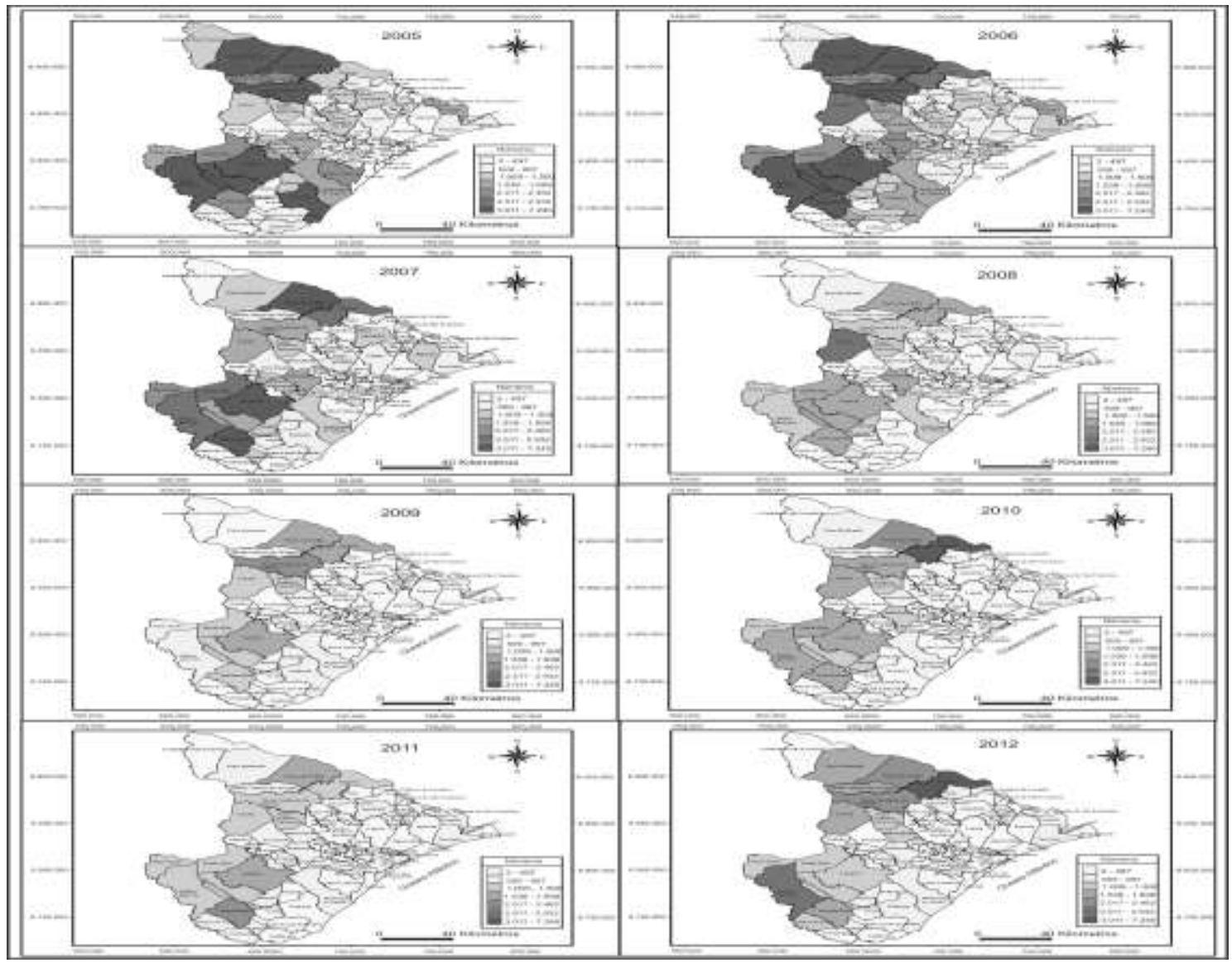

Fonte: Dados BCB/DIORF/DEROP/DIORE, 2005-2012 e Atlas SEPLANTEC, 2004.

A variação contratual entre 2005 e 2012 demonstra que o Pronaf sofreu forte decréscimo. O mesmo se mantivera positivo em $21,3 \%$ dos municípios, que mantiveram ou cresceram em termos de número de contratos. Fato evidenciado em Gararu e Carira, em que as atividades agrícolas do milho e da pecuária leiteira têm sido estimuladas pela demanda dos mercados nos últimos anos (Figura 02). A variação negativa em termos contratuais se destacou para municípios como Porto da Folha, que em 2005 tiveram contratos superiores a 3.000 e em 2012, números inferiores a 2.500, refletindo um decréscimo de 35,30\% que pode ser explicado pelas condições climáticas vivenciadas no último momento. Casos como do município de Itabaianinha se fazem interessante destacar, pois o decréscimo contratual entre 2005 e 2012 fora de apenas 4,36\%, validando momentos de intensa demanda contratual,

\footnotetext{
${ }^{7}$ Os dados expostos no conjunto de mapas refletem intervalos fechados de número de contratos realizados entre 2005 e 2012 segundo o Banco Central do Brasil.
}

DOI: http://dx.doi.org/10.22295/grifos.v30i51.5220 | Edição Vol. 30, Núm. 51, 2021. 
decréscimo e retomada de crescimento (Figura 02). A variação negativa para mais de $75 \%$ dos munícipios sergipanos demonstra como o Programa perde status junto ao agricultor, motivada pelo desconhecimento das mudanças implementadas, assim como pela apreensão do agricultor em não conseguir saldar suas dívidas com o segmento financeiro.

Figura 02- Sergipe: Variação dos contratos do PRONAF efetivados (2005-2012)

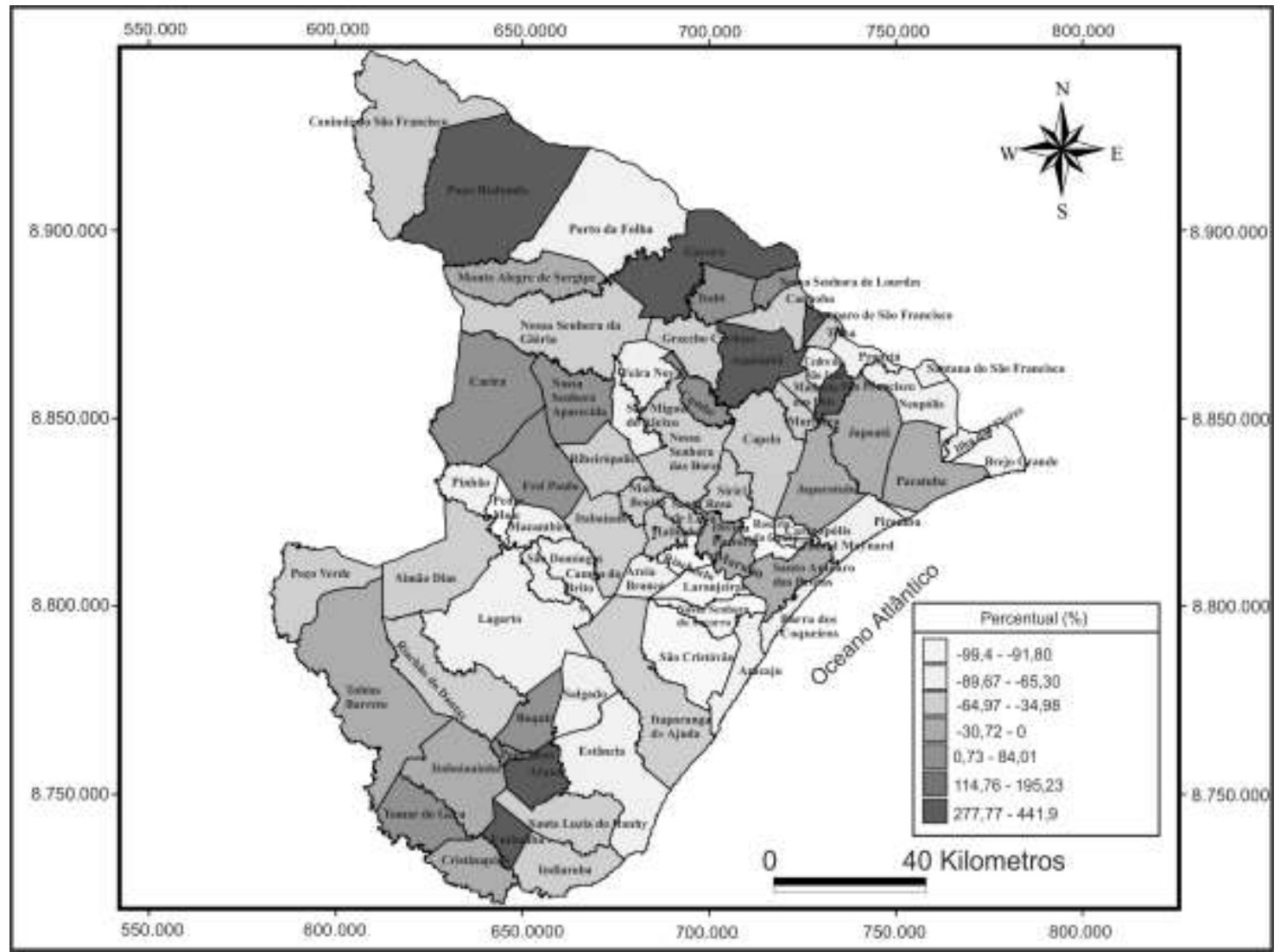

Fonte: Dados BCB/DIORF/DEROP/DIORE, 2005-2012 e Atlas SEPLANTEC, 2004.

Em relação aos montantes, observou-se quase sempre a liberação de valores superiores a 5 milhões de reais anuais por município, considerando a soma de contratos de custeio e de investimento (Figura 03). Nos três períodos analisados, correspondentes ao intervalo de 2005 a 2012, verificou-se sempre oscilação de montante liberado por municípios. Nesse tocante, de 2005 a 2006, observou-se espacialização mediana entre o número de municípios que obtiveram montantes superiores a 5 milhões de reais, como é o caso de Porto da Folha ( $\mathrm{R} \$ 8.930 .413,00$, em 2005; R\$ 9.046.441,46, em 2006) e Lagarto (R\$ 5.297.931,61, em 2005; R\$ 5.464.667,92, em 2006). A esses municípios somam-se, também, 
no ano de 2006, Nossa Senhora da Glória (R\$ 5.549.655,36) e Tobias Barreto (R\$ 5.432.457,79). Nos anos de 2005 e 2006, 46\% e 40\% dos municípios, respectivamente, receberam menos de meio milhão de reais e estiveram localizados, em quase sua totalidade, na porção litorânea, ao contrário da espacialização observada para os valores maiores, que se concentraram basicamente na porção sertaneja.

Na segunda fase (2007 a 2009), assim como no caso dos contratos, ocorreu uma diminuição do valor liberado, em função da redução sofrida nos valores para alguns municípios, verificando-se que somente o município de Lagarto manteve um montante superior a R \$ 5 milhões. Essa fase demonstra concentração de liberação de montante nos municípios sertanejos, mas com ampliação do número de municípios que obtiveram valores inferiores a cinco milhões e com ligeiro aumento na escala de até um milhão de reais. A diminuição de municípios com valores disponibilizados superiores a 5 milhões é justificada pelas condições dos agricultores para renovar contratos e, mesmo, por não se enquadrarem nas exigências pré-estabelecidas para outro financiamento ou de migração para outra modalidade. 
Figura 03- Sergipe: Montantes efetivados em contratos do Pronaf (2005-2012) ${ }^{8}$

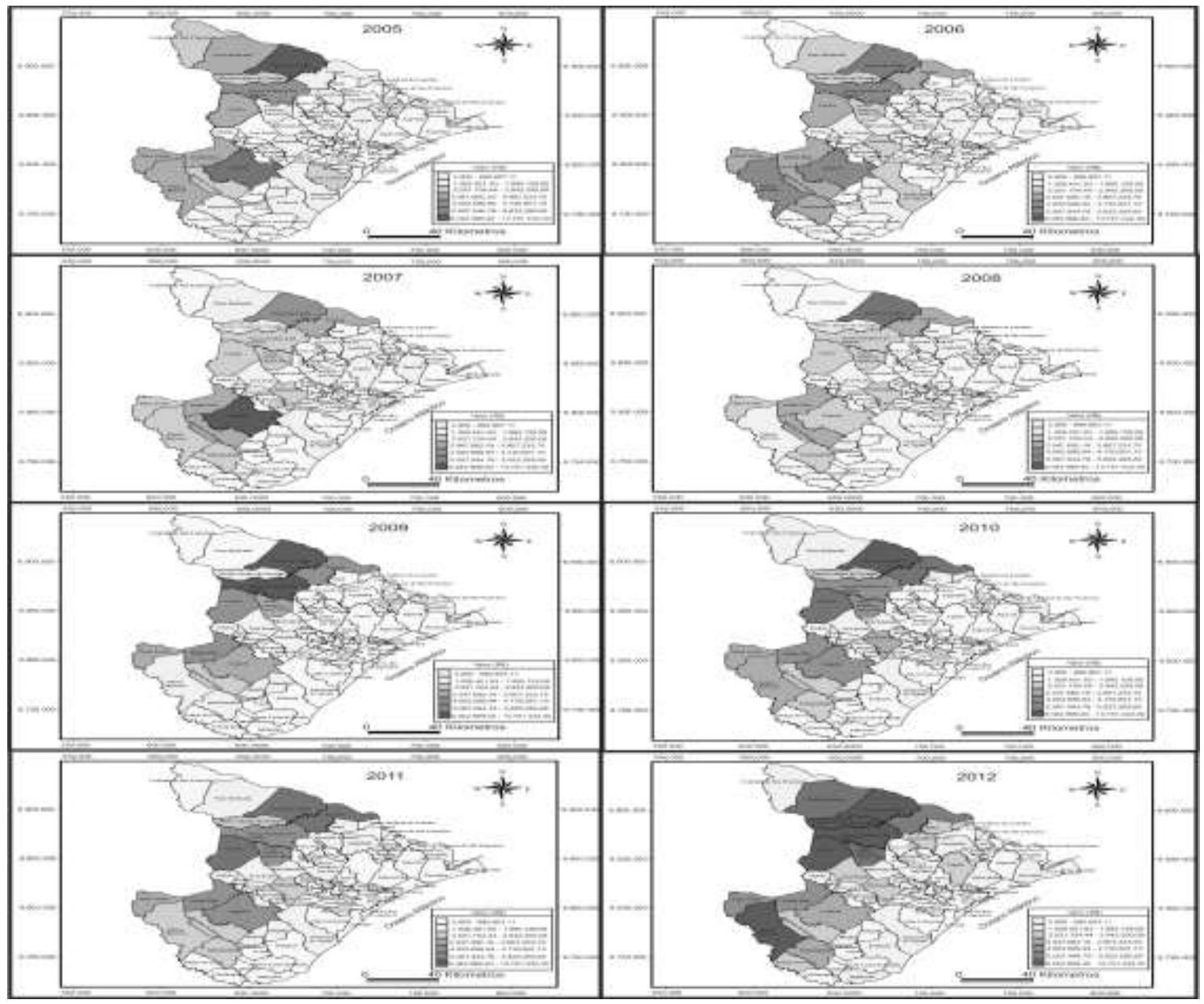

Fonte: Dados BCB/DIORF/DEROP/DIORE, 2005-2012 e Atlas SEPLANTEC, 2004.

Na terceira fase, entre 2010 a 2012, o Pronaf apresentou ligeiro aumento no número de contratos efetivados. Nesse período, cresceu o número de municípios com montantes liberados entre $\mathrm{R} \$ 5$ e pouco mais de 13 milhões de reais, concentrando-se, principalmente, no Alto Sertão e no Sul do Estado, município de Tobias Barreto. Em 2010 e 2011, foram Carira, Gararu e Porto da Folha os municípios com maior volume de montante liberado. No ano de 2012, destacaram-se oito municípios, dentre os quais: Carira, Gararu, Monte Alegre, Nossa Senhora Aparecida, Nossa Senhora da Glória, Poço Redondo, Porto da Folha e Tobias Barreto, com valores que alcançaram quase 14 milhões de reais por município. Esses valores destinaram-se à modalidade de custeio, principalmente para a produção de milho e a criação

\footnotetext{
${ }^{8}$ Os dados expostos no conjunto de mapas refletem intervalos fechados de número de montante liberado entre 2005 e 2012 segundo o Banco Central do Brasil.
}

DOI: http://dx.doi.org/10.22295/grifos.v30i51.5220 | Edição Vol. 30, Núm. 51, 2021. 
de gado leiteiro e de corte, mas também para investimentos realizados no processamento desses produtos.

Apesar dos volumes liberados pelo Pronaf, observou-se que de 2005 a 2012 a variação percentual por município sergipano também apresentou escala negativa, mas com expressividade menor, se comparada aos contratos, representando $40 \%$ do total (Figura 04). O fato é evidenciado nos municípios de General Maynard, Divina Pastora e mesmo Lagarto que tiveram valores decrescidos em, respectivamente, 98,59\% ( $\mathrm{R} \$ 1.938 .748,27), 97,67 \%$ $(\mathrm{R} \$ 315.402,5)$ e 40,52\% ( $\mathrm{R} \$ 2.146 .990,92)$. Apesar do percentual negativo, verificou-se que o montante liberado para municípios como São Francisco, Amparo de São Francisco e Gararu experimentou variações superiores a 300\%. Essas variações se justificam nas condições demarcadas por entidades institucionais, à exemplo de representantes de entidade bancária, quanto à falta de potencialidade das entidades financeiras no sentido de disponibilizar crédito e em virtude da falta de uma assistência técnica efetiva.

Figura 04- Sergipe: Variação dos montantes efetivados em contratos do Pronaf (20052012)

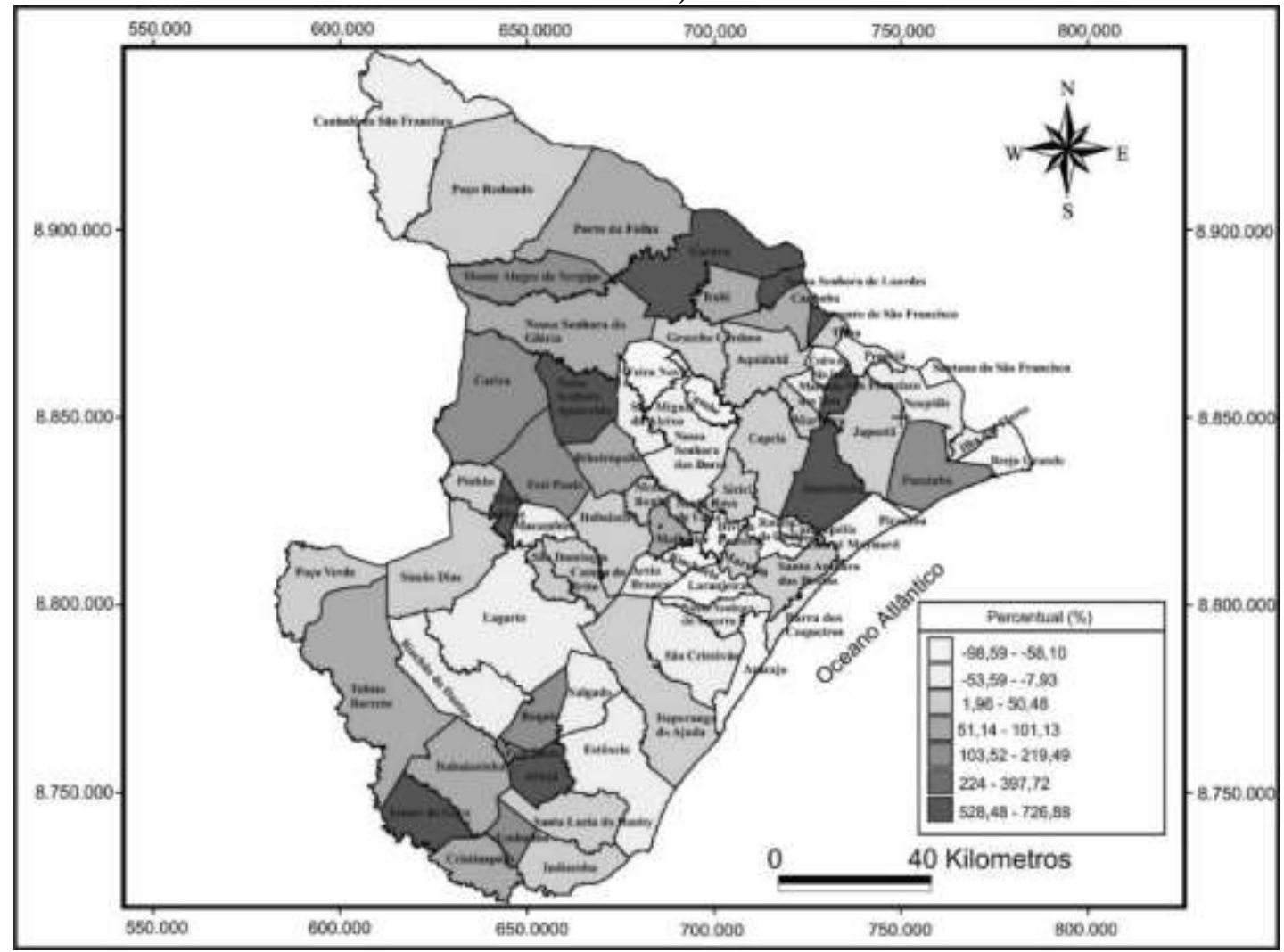

Fonte: Dados BCB/DIORF/DEROP/DIORE, 2005-2012 e Atlas SEPLANTEC, 2004. 
Deste modo, no curto intervalor de tempo analisado (2005-2012), valida-se que o programa, mesmo com suas inconstâncias contratuais e de montante liberados, torna-se, pela função agregada, um estímulo para grande número de famílias rurais que vivem e dependem da atividade agropecuária, sobretudo. A conjugação do financiamento e produção repercute ainda, na melhoria técnico-produtiva e por conseguinte, no crescimento econômico local e sustentável, a partir do aumento da capacidade produtiva, da geração de empregos e da melhoria da renda.

\section{RELAÇÃO PRONAF E MELHORIAS TÉCNICO-PRODUTIVAS EM SERGIPE}

O estado de Sergipe conta com 100.606 estabelecimentos rurais (2006), ocupando uma área de 1.480.414 hectares (IBGE, 2009). Desse total, 90.330 são estabelecimentos familiares (89,78\%), com uma área de 711.488 hectares (48\% do total estadual), configurando área média de 7,87 hectares por estabelecimento familiar (Tabela 01). Neste contexto, a agricultura familiar em 2006 estava concentrada, sobretudo, na porção centro-sul do Estado, em estabelecimentos que variam de 80 a 240 hectares, excluindo-se o município de Tobias Barreto, no qual os estabelecimentos familiares podem chegar a até 280 hectares, conforme a definição dos 4 módulos fiscais (Sistema Nacional de Crédito Rural -SNCR, 2001). Nesse momento, acreditava-se que haveria divisão de unidades familiares conforme compartilhamento por herança9 9 .

Tabela 01- Sergipe: Número de estabelecimentos agrícolas e área total e familiar(2006)

\begin{tabular}{l|c|c}
\hline \multicolumn{1}{c}{ Variáveis } & \multicolumn{2}{c}{2006} \\
\hline \multirow{2}{*}{ Número de Estabelecimentos } & Total & Agricultura Familiar \\
\cline { 2 - 3 } Área (há) & 100.606 & 90.330 \\
\hline Área por estabelecimento & 1.480 .414 & 711.488 \\
\hline
\end{tabular}

Fonte: Censo Agropecuário 2006 (IBGE, 2009).

\footnotetext{
9 Mas os dados do Censo de 2017, já demonstram que houve concentração de terras junto as grandes propriedades, pois foram recenseados 72.060 estabelecimentos familiares, com área de 680.515 hectares, que perfaz área média de 9,44ha.
} 
As receitas dos estabelecimentos da agricultura familiar são potencialmente advindas das atividades agropecuárias $\left(93,7 \%\right.$ da renda de 60.814 estabelecimentos - IBGE, 2006) ${ }^{10}$. Esse número demonstra como o estado de Sergipe ainda mantém a agricultura como fonte central na geração da renda, apesar de se observar que novas atividades estão sendo inseridas, muitas vezes de modo complementar.

Os dados mostram que as atividades complementadoras de renda advêm, sobretudo, da instalação de agroindústrias (4.139) para processamento do que é produzido no Estado; de receitas oriundas da aposentadoria e pensão, presentes em cerca de $22 \%$ dos estabelecimentos familiares, responsáveis pelo repasse de até $10 \%$ da renda total do que é produzido por esses estabelecimentos; de salários obtidos em atividades fora da unidade produtiva de 7.235 estabelecimentos, que geram cerca de $4 \%$ da renda total; e de programas especiais do Governo Federal, a exemplo do Bolsa Família, presente em 10.687 estabelecimentos com representação de 1,3\% da renda total rural do Estado (IBGE, 2006).

Diante disso, a questão do financiamento ganha relevância, por condicionar ampliação à produção agropecuária, sem desconsiderar que essa prática, ao associar a produção às lógicas do mercado, está integrando a agricultura familiar às dinâmicas do capital. Dados do Censo Agropecuário (2006) demonstraram que 13.572 estabelecimentos obtiveram algum tipo de financiamento, segmentado nas seguintes modalidades de investimento, custeio, comercialização e manutenção do estabelecimento (Gráfico 03) $)^{11}$.

\footnotetext{
10 Em relação ao Censo de 2017, houve um decréscimo de unidades familiares cuja renda advém prioritariamente da atividade na unidade produtiva (57.096 estabelecimentos familiares com a geração de renda de $\mathrm{R} \$ 897.258$ (mil reais). Fato que pode estar associado a unidades de final de semana ou mesmo sem produção. Além desses valores produtivos, as unidades contam com outras atividades na própria unidade que gera renda de $\mathrm{R} \$ 46.364$ (mil reais) e com receitas advindas externamente, que somam $\mathrm{R} \$ 656.621$ (mil reais) (IBGE, 2019).

${ }^{11}$ No Censo de 2017, o número de estabelecimentos familiares que acessaram algum tipo de financiamento ficou em 8.234, decréscimo de quase $40 \%$ em relação ao Censo de 2006. Esse financiamento ficou distribuído em 5.521 estabelecimentos que obtiveram para investimento, 3.459 para custeio, 215 para comercialização e 775 para manutenção do estabelecimento. O respectivo decréscimo pode estar associado a insegurança dos mercados, por condições políticas, assim como pela modificação de regras bancárias e de financiamentos.
} 
Gráfico 3 - Tipos de financiamento por modalidade (2006)

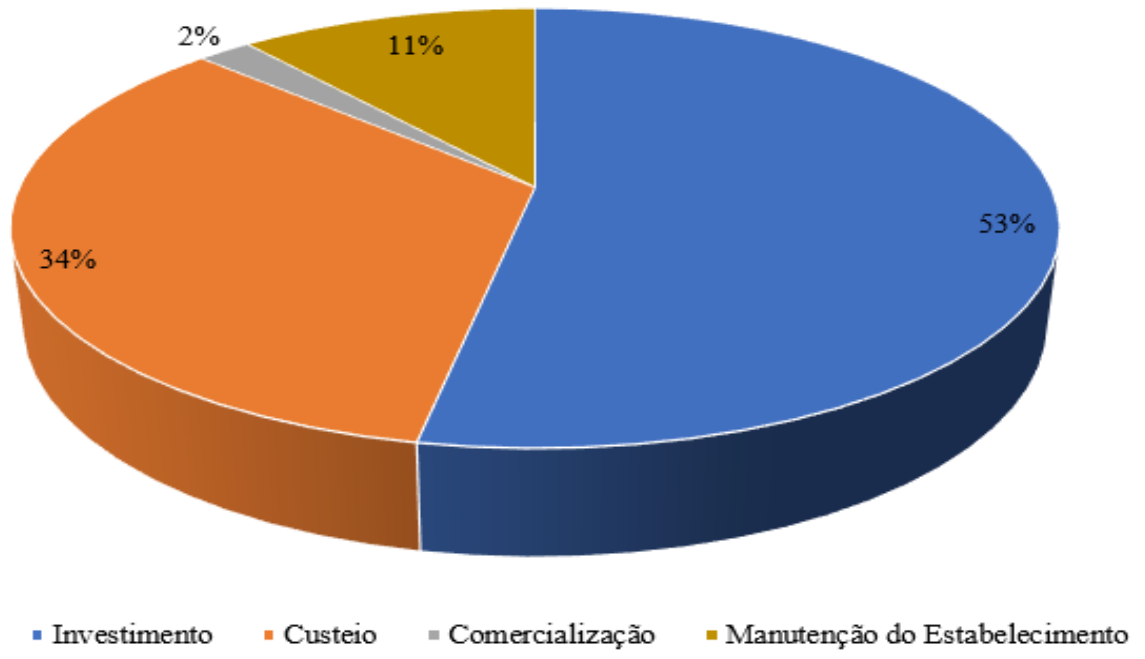

Fonte: IBGE (2009).

Cerca de 13,5\% dos estabelecimentos familiares existentes em Sergipe contaram em 2006 com o apoio de financiamentos de investimento e de manutenção, para auxiliar na aquisição de maquinários e na construção de infraestruturas de armazenamento, sobretudo. Pelo exposto, evidencia-se o ganho de importância do Pronaf e alicerça-se a afirmativa de que tem contribuído para o desenvolvimento local-regional, haja vista impulsionar as economias municipais e potencializar o desenvolvimento rural. Isso é visualizado no interior sergipano, com a inserção técnico-produtiva. A análise das entrevistas realizadas com 76 agricultores beneficiários do Pronaf pesquisados ${ }^{12}$, ficou visível por meio da aplicação dos questionários, a importância que teria a efetiva ação das instituições de Assistência Técnica e Extensão Rural (ATER) na transferência de conhecimentos, de técnicas e promoção produtiva das unidades familiares.

A Assistência Técnica e Extensão Rural (ATER) se fez presente em 65\% das unidades analisadas, sendo que, antes do Pronaf, apenas $27 \%$ dos agricultores eram beneficiados com

\footnotetext{
12 A pesquisa de campo deu-se no ano de 2014, mediante o compartilhamento de dados do Banco do Nordeste (2012), por meio dos quais foi possível observar os municípios com maior quantitativo de contratos efetivados por modalidade de Pronaf: Capela (Pronaf A), Itabaianinha (Pronaf B-Agroamigo) e Carira (Pronaf Comum). A amostragem foi calculada mediante a soma dos resultados observados nos três municípios e, a partir disso, estabeleceu-se que a soma era $100 \%$; desse percentual, calculou-se o grau de representatividade de cada valor municipal frente ao total de 1.524 operações. Por essa proporcionalidade retiramos o percentual de cada caso, perfazendo a amostra total de contratos de cada município, totalizando 76 agricultores a ser entrevistado.
} 
esse serviço. Todavia, o número de agricultores que apontaram nunca ter recebido nenhum tipo de assistência técnica foi muito elevado $(23,5 \%)$, considerando que uma das bases de sustentação do Programa é o acompanhamento técnico de entidades público-privadas (CARVALHO, 2016). A ausência nesse acompanhamento é justificada pelo baixo número de técnicos efetivos trabalhando na prestação de serviços das ATER, que dirime a condição de trabalho a sorteio de áreas por amostragem.

Ademais, o grau de satisfação em relação à assistência técnica recebida pelos beneficiários do Pronaf demonstra que existe agricultores satisfeitos, insatisfeitos, muito satisfeitos e aqueles que não opinaram em relação ao acompanhamento recebido (Gráfico 4). O grau de satisfação reflete a assistência técnica definida mesmo em grupo, apesar de muitos desses agricultores alegarem que poderia ser melhor, se o técnico pudesse ir até a unidade produtiva. Mas, ainda assim, os agricultores afirmaram terem sido informados sobre técnicas de produção para lavoura (43,5\%), técnicas de conservação do solo (32\%), técnicas para criação de animais $(25,9 \%)$, dentre várias outras.

Gráfico 04 - Grau de Satisfação com a Assistência Técnica Recebida (2014).

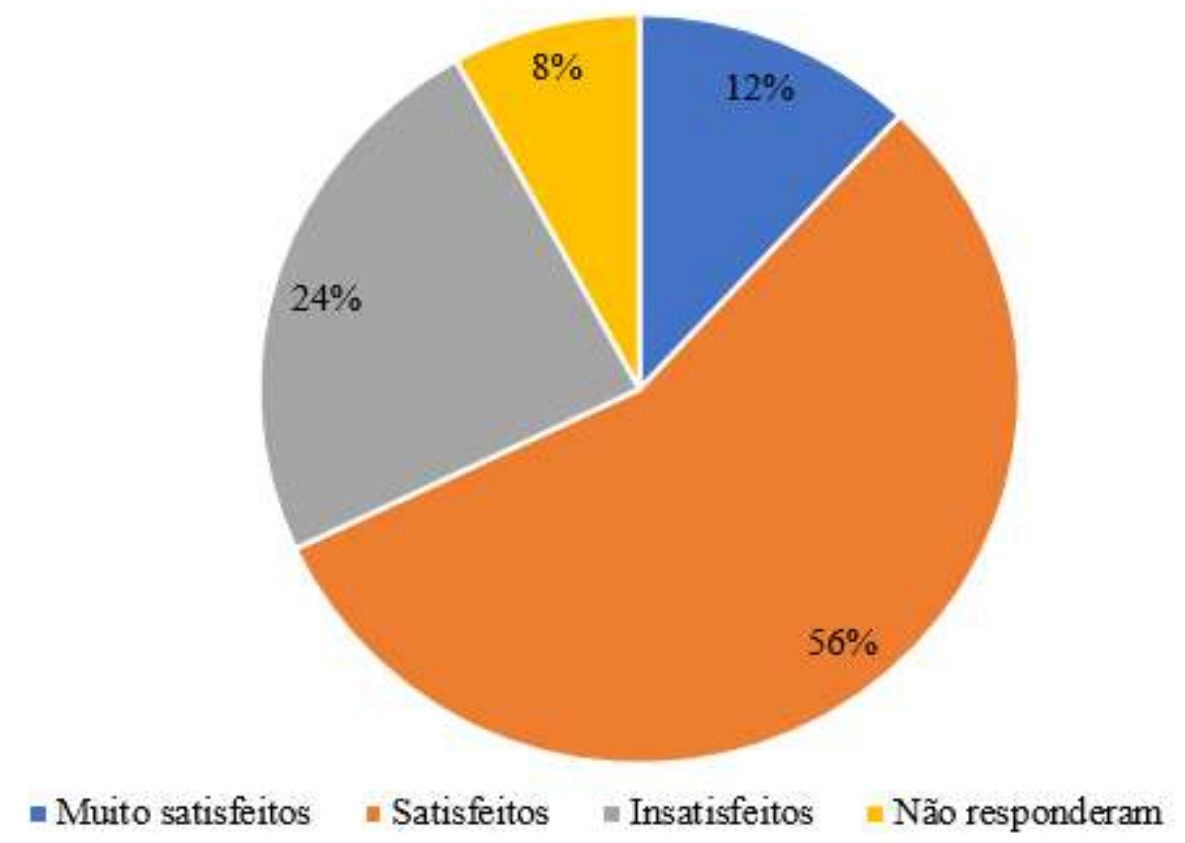

Fonte: Pesquisa de campo (2014). 
As unidades pronafianas de Sergipe demonstraram que tem havido inserção do processo tecnológico em suas práticas agropecuárias, seja nos assentamentos, seja nos pequenos estabelecimentos e, mesmo, nos estabelecimentos com produção voltada exclusivamente para o mercado, fato justificado pelo aumento de quase $30 \%$ na utilização de tração mecânica após acesso ao Pronaf. Outra mudança observada em relação à tração mecânica deu-se na aquisição dos equipamentos por agricultores familiares que, entre o antes e o depois, aumentou em $150 \%$. O contexto demonstra que, mesmo antes do Pronaf, o agricultor familiar sergipano conhecia os benefícios oferecidos pela tração mecânica, em termos de diminuição de trabalho humano e eficácia, apesar dos possíveis danos ao solo. Contudo, não se pode desconsiderar o aumento em termos de tração animal $(16,6 \%)$, motivado pela existência do equipamento no estabelecimento e como forma de diminuir custos. A utilização de aparato tecnológico repercute na diminuição do trabalho humano, no que se refere à tração manual (-11\%).

Ainda nessa questão, e considerando-se o antes e o depois do Pronaf, observou-se o crescimento total em $22,2 \%$ em termos de utilização e aquisição de equipamentos pelo total de unidades analisadas em Sergipe. Alguns equipamentos tiveram forte ampliação após acesso ao Pronaf, caso da adubadeira $(300 \%)$, roçadeira $(100 \%)$, motor de moer capim $(100 \%)$, semeadeira (66,6\%), trator (40,8\%), pulverizador (30\%), entre outros. Alguns desses equipamentos já perfazem aquisição do agricultor, isto é, fora adquirido com finalidade de uso e de locação; sendo que a maioria desses pronafianos ainda costumam locar o equipamento e o trabalho profissional que os manuseiem (CARVALHO, 20016).

Além disso, há uma melhoria nas condições de trabalho nas unidades familiares, expressa no uso de equipamentos mecânicos e na diminuição do uso de ferramentas manuais $(-1,3 \%)$ tais como enxadas, foices, facões etc., tradicionalmente utilizados no espaço rural. Essa diminuição pode estar aliada, sobretudo, à mudança de atividades desenvolvidas no estabelecimento, a exemplo da opção pela pecuária que requer menos equipamentos desse tipo para a lida com os animais.

$\mathrm{Na}$ esteira da modernização, houve a demarcação aplicativa de insumos mais avançados, no que tange à opção por mudas e sementes com melhoria genética, além do uso de insumos sofisticados, a exemplo do NPK 103010 (527,9\%), vermífugos (557,1\%), inseticidas $(239,08 \%)$, herbicidas $(168,7 \%)$, rações animais $(156 \%)$, carrapaticidas 
(112,76\%), entre outros (CARVALHO, 2016). Esse aspecto mostra que o agricultor familiar tem agregado conhecimento de insumos auxiliares na alimentação animal e no combate às pragas e doenças, mas, muitas vezes, utilizados de modo exagerado, com riscos de danos às culturas e ao ser humano (em função da manipulação indevida desses insumos, mas também em razão do consumo dos produtos contaminados), assim como promove a infertilidade do solo.

A utilização de todos esses insumos, principalmente após o acesso aos recursos do Pronaf, demonstra que o pequeno agricultor tem buscado alavancar sua produção de modo a se integrar às demandas de mercado, desconsiderando a insustentabilidade e a tradição produtiva, que se fazia desvinculada dos insumos químicos. Tal fato é evidenciado principalmente em Carira, cuja produção de milho, além de atender à demanda interna, também é entregue a grandes empresas produtoras de rações e alimentos de outros Estados, especialmente do oeste baiano, bem como para alimentação de aves no estado do Pernambuco.

\section{CONSIDERAÇÕES FINAIS}

O intuito do texto foi analisar a evolução e as mudanças socioespaciais promovidas pelo Pronaf em Sergipe, em termos de inserção técnico-produtiva, através de dados do Banco Central (2005-2012), do Instituto Brasileiro de Geografia e Estatística (IBGE) e da pesquisa de campo que contemplou 76 agricultores familiares beneficiários do Programa. Por esses meios, observou-se inúmeras variações quali e quantitativas, que define o Programa Nacional de Fortalecimento da Agricultura Familiar como uma alternativa concreta a mudanças socioprodutivas no espaço rural sergipano, haja vista a potencialidade que gesta no sentido de subsidiar possibilidades de emprego e renda, não só no campo, mas também no espaço urbano junto as economias locais, através dos mercados alicerçados na aquisição de insumos e comercialização de agrícolas.

O Programa tornou-se um estímulo ao crescimento, ao tempo que se define em conjunto com as políticas sociais, como um instrumento de inclusão social para o agricultor familiar. O Pronaf deve ser, de fato, um programa que promova equidade social e 
melhoramento dos níveis de renda, ao promover maior produção agrícola no campo e promover a inserção de novas ocupações não-agrícolas.

O Programa ainda apresenta problemas quanto à inserção conjuntural de uma categoria, que se delimita por nível de renda. Contudo, o Pronaf é uma alternativa concreta para diversos segmentos sociais da agricultura familiar brasileira e sergipana, que era relegada das políticas públicas nacionais. Na curta trajetória trabalhada (2005-2012), diversas mudanças institucionais foram implementadas, contribuindo para a ampliação da capilaridade do Programa. Assim, em seus 24 anos de operacionalização, o Pronaf ganhou destaque nacional, estando presente em praticamente todos os municípios brasileiros e, por conseguinte, em todo o estado de Sergipe.

No espaço rural sergipano, o Programa tem, gradativamente, contribuído para a diversificação da produção, que passa a contar com inúmeras mudanças de ordem técnica e operacional, sendo isso uma variável constante, e, por conseguinte, uma correspondência às demandas do mercado. Isso decorre da absorção do processo modernizador entre os agricultores familiares que, mesmo atuando de modo individualizado, de acordo com os seus próprios interesses, sustentam mudanças na organização do espaço rural.

Diante dessa conjuntura, verifica-se que o Pronaf foi um possibilitador de alterações significativas, fruto da agregação de assistência técnica, de utilização de implementos tecnológicos e de insumos para a produção agropecuária dos municípios. Neste contexto, o Estado não deve ser provedor apenas de recursos, mas de mão de obra especializada, sobretudo em Sergipe, com intuito de assistir esses agricultores de forma mais direta e precisa, no sentido de análise de solo, de produção mais conveniente e de aconselhamento quanto a logística de demandas do mercado.

O programa rompeu com o tradicional sistema de crédito rural brasileiro, no momento em que passou a observar os excluídos de crédito do campo. Todavia, precisa certifica-se de sua atuação junto a pequenos agricultores, haja vista, pesquisas já pontuarem uma atenção maior desse programa às categorias mais abastadas da agricultura familiar. Logo, faz-se necessário a constância em termos de atualização e análise de dados disponibilizados pelo Banco Central, assim como por outras instituições executoras do Pronaf, a fim de potencializar o impacto econômico-financeiro desse crédito na vida dos agricultores e nas economias locais. Além disso, estimular a promoção de novas pesquisas junto ao agricultor 
pode contribuir para um retrato mais amplo quanto as melhorias socioprodutivas e de ampliação de renda no campo brasileiro, assim como revalorizar a ideia de promoção de equidade social, a partir da avaliação de quão heterogênea é esse ator social rural.

\section{AGRADECIMENTOS}

Agradecimento CAPES (Coordenação de Aperfeiçoamento de Pessoal de Nível Superior) pelo apoio financeiro, na condição de bolsista de doutorado (2012/2016), realizado na Universidade Federal de Sergipe.

\section{REFERENCIAS}

AQUINO, J. R.; SCHNEIDER, S. O Pronaf e o desenvolvimento rural brasileiro: avanços, contradições e desafios para o futuro. In: GRISA, C. e SCHNEIDER, S. Políticas públicas de desenvolvimento rural no Brasil. Porto Alegre: Editora da UFRGS, 2015. p. 53-82.

BANCO CENTRAL DO BRASIL (BCB). Anuário Estatístico do Crédito Rural. 20052012. Disponível em https://www.bcb.gov.br/acessoinformacao/legado?url=https:\%2F\%2Fwww.bcb.gov.br\%2F Default.asp\%3Fid\%3DRELRURAL\%26ano\%3D2011>. Acesso em: 09 jan. 2014.

BANCO CENTRAL DO BRASIL (BCB). MCR - Manual de Crédito Rural. 2012. Disponível em < http://atividaderural.com.br/artigos/5029a0a07fc48.pdf>. Acesso em: 15 abr. 2013.

BANCO CENTRAL DO BRASIL (BCB). Atualização MCR 651. 2018. Disponível em < https://www3.bcb.gov.br/mcr/completo>. Acesso em: 29 jul. 2020

BANCO DO NORDESDE DO BRASIL (BNB). Sobre o Agroamigo. Disponível em https://www.bnb.gov.br/agroamigo/sobre-o-agroamigo>. Acesso em: 04 ago. 2020.

CARVALHO, D. M. de. Trajetórias do Pronaf em Sergipe. São Cristóvão: PPGEO/UFS, 2016 (Tese de doutorado).

CARNEIRO, M. J. Política pública e agricultura familiar: uma leitura do Pronaf. Revista Estudos Sociedade e Agricultura. Rio de Janeiro, v. 5, n. 1, p. 70-82, 1997.

CARNEIRO, M. J.; PALM, J. L. Informando Política Pública: uma revisão bibliográfica sobre Pronaf e qualidade de vida (2006-2013). Revista Raízes. v. 36, n. 1, p. 61-74, 2016. 
DINIZ, D. M. et al. (Coords.). Textos para a História de Sergipe. Aracaju: UFS/Banese, 1991.

GUANZIROLI, C. E. PRONAF dez anos depois: resultados e perspectivas para o desenvolvimento rural. Rev. Econ. Sociol. Rural. Brasília, Vol.45, nº.2, p. 301-328, 2007.

HEREDIA, B. M. A.; CINTRÃO, R. P. Gênero e acesso a políticas públicas no meio rural brasileiro. Revista Nera. Presidente Prudente: Ano 9, N. 8, p. 301-328, 2006.

IBGE. Censo Agropecuário 2006. Agricultura Familiar. Primeiros Resultados. Brasil, Grandes Regiões e Unidades da Federação. Brasília/Rio de Janeiro. MDA/MPOG, 2009.

IBGE. Censo Agropecuário 2017: resultados definitivos. Rio de Janeiro: IBGE, 2019.

IBGE. Tabela: 1258 - Número de estabelecimentos, Área, Valor total da produção, Renda, Despesa e Financiamento dos estabelecimentos agropecuários, segundo indicadores da agricultura familiar e não familiar - FAO. Disponível em

<https://sidra.ibge.gov.br/Tabela/1258>. Acesso em: 12 dez. 2013.

MDA/CONDRAF. Diretrizes Para o Desenvolvimento Rural Sustentável. 2006.

Disponível em

$<$ http://www.faper.org.br/index.php?option=com_docman\&task=doc_download\&gid=5\&It emid=106>. Acesso em: 08 jul. 2012.

MDA. Plano Safra da Agricultura Familiar 2013/2014: transformando vidas. Plantando o futuro. Disponível em <http://portal.mda.gov.br/plano-safra-2013/>. Acesso em: 03 mai. 2014.

MATTEI, L. Impactos do Pronaf: Análise de Indicadores. Brasília: Ministério do Desenvolvimento Agrário, Núcleo de Estudos Agrário e Desenvolvimento Rural (NEAD Estudos), 2005.

MATTEI, L. Evolução do crédito do PRONAF para as categorias de agricultores A e A/C entre 2000 e 2010. In: Revista Econômica do Nordeste. Fortaleza: v. 45, n. 3, p. 58-69, 2014.

MOTA, W. da L.; SANTANA, J. R. de. O Microcrédito como Estratégia de Redução da Pobreza no Nordeste: uma Avaliação a partir do Programa Crediamigo. Revista

Econômica do Nordeste (REN). Fortaleza, vol. 42, nº 01, 2011.

NORTH, D. C. Understanding the process of economic Change. Princeton: Princeton University Press, 2005.

NORTH, D. C. Institutions, Institutional Chance and Economic Performance. 2. ed. Cambridge University Press, 2007. 
Plano Safra. Plano Safra da Agricultura Familiar fortalece e amplia políticas públicas. 2009/2010. Disponível em <http://www.pronaf.gov.br>. Acesso em: 16 jun. de 2010.

R7. Sergipe tem 103 mil afetados pela seca. Disponível em < http://noticias.r7.com/cidades/noticias/sergipe-tem-103-mil-afetados-pela-seca-20120420.html>. Acesso em: 06 out. 2014.

SCHNEIDER, S.; CAZELLA, A. A.; MATTEI, L. Histórico, caracterização e dinâmica recente do PRONAF - Programa Nacional de Fortalecimento da Agricultura Familiar. In: SCHNEIDER, S.; SILVA, M. K.; MARQUES, P. E. M. (Orgs.). Políticas Públicas e Participação Social no Brasil Rural. Porto Alegre: UFRGS, 2004, p. 21-49.

SILVA, J. A. PROINF no território da cidadania do médio sertão de Alagoas: um caminho para o desenvolvimento territorial rural? São Cristóvão, 2018. (Dissertação de Mestrado).

TOLEDO, E. A extinção do Ministério do Desenvolvimento Agrário, um destino resignado! Jornal Boa Vista. Disponível em < https://jornalboavista.com.br/15012019aextincao-do-ministerio-do-desenvolvimento-agrario-um-destino-resignado >. Acesso em: 29 jul. 2020.

ZAAR, Miriam-Hermi. Las Políticas Públicas Brasileñas y la Agricultura Familiar: Quince Años del Programa Nacional de Fortalecimento da Agricultura Familiar (PRONAF). Scripta Nova. Revista Electrónica de Geografía y Ciencias Sociales. [En línea]. Barcelona: Universidad de Barcelona, vol. XV, nº 351, p. 741-798, 2011. 